\title{
Relationship between jaw opening force and hyoid bone dynamics in healthy elderly subjects
}

This article was published in the following Dove Press journal:

Clinical Interventions in Aging

3 April 2017

Number of times this article has been viewed

\section{Hiromichi Shinozaki \\ Haruka Tohara \\ Mariko Matsubara \\ Nobuhiro Inokuchi \\ Yasuhiro Yamazaki \\ Ayako Nakane \\ Yoko Wakasugi \\ Shunsuke Minakuchi}

Department of Gerodontology,

Tokyo Medical and Dental University,

Tokyo, Japan
Correspondence: Haruka Tohara Department of Gerodontology, Tokyo Medical and Dental University, I-5-45 Yushima, Bunkyo-ku, Tokyo, Japan

Tel/fax +8I 358035559

Email haruka-t@rd5.so-net.ne.jp
Purpose: This study aimed to examine the relationship between jaw opening force and hyoid bone dynamics and resting position in elderly individuals based on gender.

Subjects and methods: Subjects were 36 healthy elderly individuals aged $\geq 65$ years without dysphagia ( 16 men and 20 women; mean age 75.5 years, range 65-88 years). Videofluorographic images during the swallowing of $10 \mathrm{~mL}$ of $40 \%(\mathrm{w} / \mathrm{v})$ barium sulfate were obtained and the degrees of anterior, superior, and hypotenuse displacements of the hyoid bone and maximum/ resting hyoid position were evaluated. Jaw opening force was measured three times using a jaw opening force sthenometer; the mean of these three measurements was used for analysis.

Results: In men, there was a positive correlation between jaw opening force and resting hyoid position and negative correlations among all the degrees of anterior, superior, and hypotenuse displacements of the hyoid bone. In women, there was no statistically significant correlation between jaw opening force and any of the measurement items. There was no statistically significant correlation between jaw opening force and maximum hyoid position in either men or women.

Conclusion: Our findings suggest that low jaw opening force leads to low resting hyoid position only in elderly men, and a lower hyoid position in healthy elderly men results in a larger total amount of hyoid displacement during swallowing. Moreover, a maximum hyoid position in healthy individuals of either gender does not differ depending on their jaw opening force.

Keywords: aging, deglutition disorders, dysphasia, gender differences

\section{Introduction}

Movement of the larynx and hyoid bone is one of the important factors during swallowing to ensure that food boluses are smoothly carried to the esophagus without aspiration; however, reduced hyoid elevation is a common cause of aspiration in the elderly. ${ }^{1,2}$ Perlman et $\mathrm{al}^{3}$ reported that reduced hyoid elevation was associated with a 3.5 -fold greater risk of aspiration. Moreover, Furukawa ${ }^{4}$ reported that the potential for dysphagia is increased if the position of the hyoid bone, which lowers with age, is not compensated by increased elevation during swallowing. Thus, given the significant implications of hyoid bone motion analyses in swallowing dynamics, various studies have investigated and quantified superior and anterior displacements of the hyoid bone during swallowing by means of videofluorography (VF). ${ }^{1,2}$ Lateral VF imaging studies have found that anterior displacement of the hyoid bone is involved in the upper esophageal sphincter opening, whereas superior displacement is involved in laryngeal closure. ${ }^{5,6}$ In the anterior displacement of the hyoid bone, movement is primarily of the geniohyoid, whereas the anterior belly of the digastric muscle works in an auxiliary capacity. Meanwhile, in the superior displacement of the hyoid bone, the mylohyoid is the primary muscle and the posterior belly of the digastric muscle 
works as the auxiliary muscle. ${ }^{7}$ Considering dynamic allocation, it is apparent that there is an effect of suprahyoid muscle strength on hyoid dynamics and its position. However, it is difficult to measure suprahyoid muscle strength directly. Making use of the mutual movement of the suprahyoid muscles, which include the jaw-opening muscles and the hyoid elevators, we developed a meter to measure jaw opening force as a simple means to evaluate swallowing function. ${ }^{8}$ Jaw opening force is correlated with grip strength, which is an indicator of systemic muscle strength. ${ }^{8}$ As compared with healthy adults, healthy elderly individuals have significantly reduced jaw opening force. ${ }^{9}$ Moreover, reduced jaw opening force has been suggested to increase the risk of aspiration and pharyngeal residue. ${ }^{10}$ However, the relationship between jaw opening force and hyoid bone dynamics has not fully been understood. Therefore, the aim of this study was to investigate the relationship between jaw opening force and hyoid bone movement and its position in the healthy elderly based on gender.

\section{Subjects and methods Subjects}

This was a cross-sectional, observational study. Subjects were 36 community-dwelling healthy individuals aged $\geq 65$ years (16 men and 20 women; mean age 75.5 years, range 65-88 years) who underwent health examinations as outpatients between September and November 2015. All of them lived independently. People having difficulty with communication and physical function were excluded. We also excluded people who had arthrosis of the temporomandibular joint and limited jaw opening. Those with any history of undergoing treatment or rehabilitation for dysphagia and those with cerebrovascular disease and/or neuromuscular disease were excluded. The study protocol was approved by the ethics committee of Tokyo Medical and Dental University School of Dentistry (approval number: 1143), and written informed consent was obtained from all subjects and their families after receiving an explanation of the study. After estimating a Spearman's correlation coefficient of 0.678 for quantitative variables (coinciding with the value determined in similar studies), ${ }^{11} P=0.05$, and a power of 0.80 for a bilateral hypothesis, the sample size was found to be 12 individuals ( $G$ *Power 3.1 software; Kiel University, Kiel, Germany).

\section{Procedure}

Lateral VF images were taken at a speed of 30 frames/s using the digital X-ray TV system Flexavision (Shimadzu Medical Systems Corp, Osaka, Japan) and video recorded with a digital recorder (DV-AC82; Sharp Corporation, Osaka, Japan).
Afterward, the video was converted to MP4 format and loaded on to a personal computer. During analysis, subjects were sitting on the chair at a $90^{\circ}$ angle with their necks in the intermediate position, lead spheres measuring $14.3 \mathrm{~mm}$ in diameter were attached as markers to the cervical spine of the subjects. An investigator then injected $10 \mathrm{~mL}$ of $40 \%(\mathrm{w} / \mathrm{v})$ barium sulfate into the sublingual region of the subject using a syringe. The subjects were instructed to swallow freely at their own pace, and the obtained image data were used to evaluate the movement of the hyoid during swallowing. ${ }^{12}$

Jaw opening force was measured by a dentist with clinical experience of treating dysphagia patients by means of a jaw opening force sthenometer (Livet Inc., Tokyo, Japan; Figure 1). The jaw opening force sthenometer is composed of a cap that covers the head, an adjustable chin cup fitted with two belts, and a force meter. The head cap is placed over the head and the chin cup is placed underneath the chin and fastened as tightly as possible to prevent the jaw from opening with adjustable belts. Since the distance between the head and mandible and head circumference differed among participants, the belts were adjustable with a hook. The jaw-opening sthenometer was calibrated to zero before each measurement. The subjects were seated comfortably on a chair with their head in a relaxed and intermediate position. Once the apparatus was fitted, the subjects were instructed to open their mouths to the maximum to measure jaw opening force in Newton $(\mathrm{N})$. Measurements were taken three times, and the mean of the three measurements was used for analysis.

\section{Hyoid position and displacement measurement methods}

A coordinate system was established with the $y$-axis forming a straight line connecting the lower ends of the second and

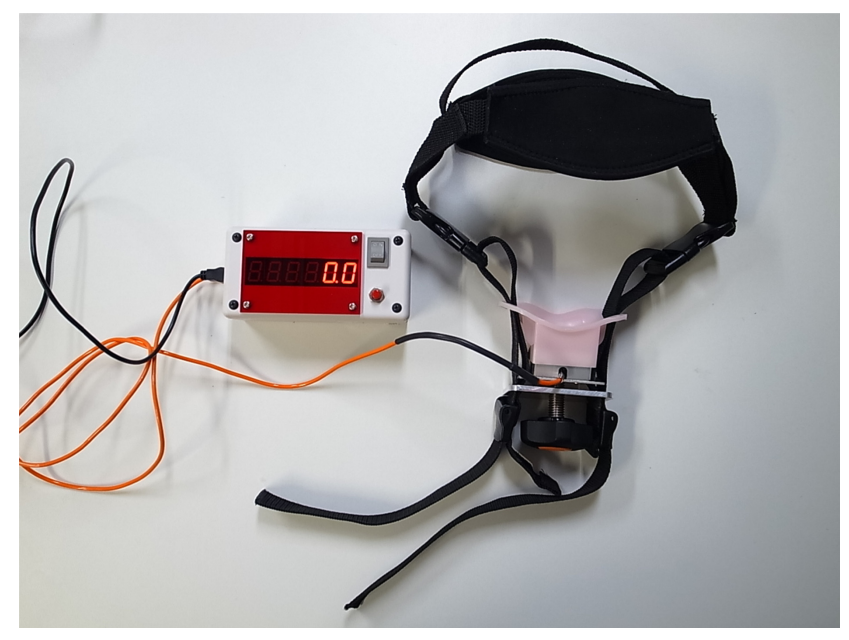

Figure I Jaw-opening sthenometer. 


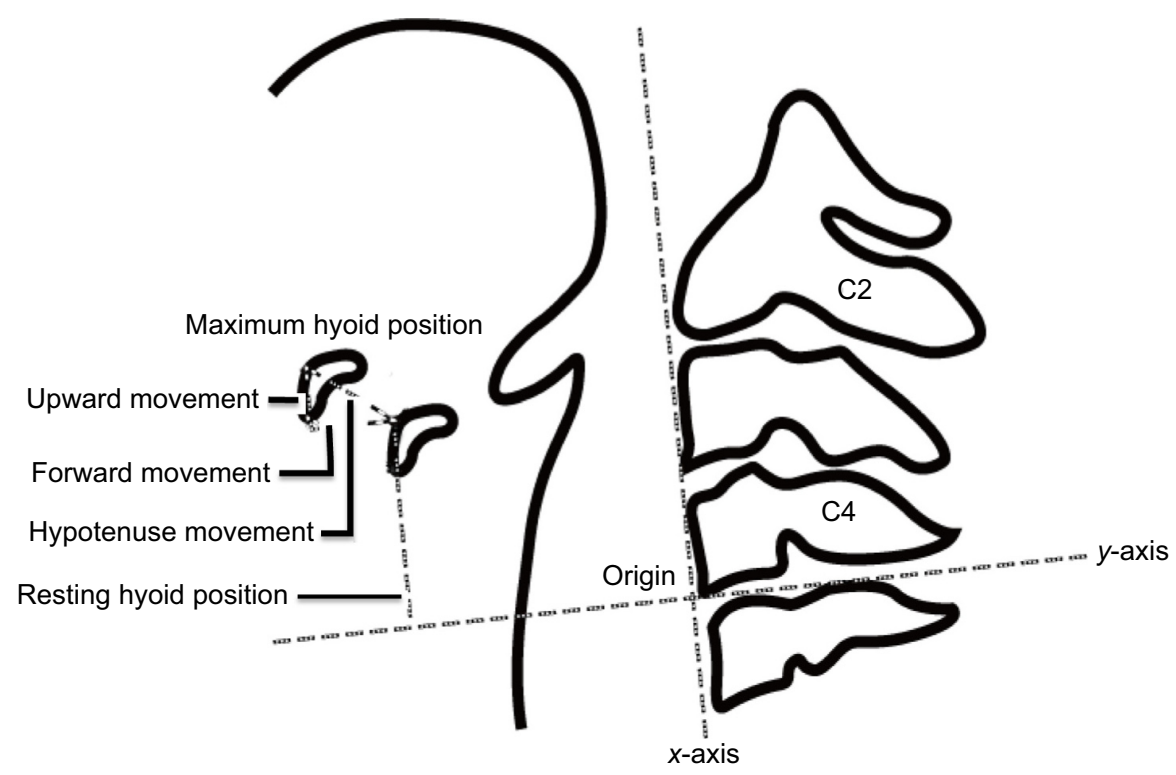

Figure 2 Schema of a lateral view of hyoid bone and neck with measuring point.

Note: Maximum/resting hyoid position: the vertical distance from the upper end of the hyoid bone to the $y$-axis.

fourth cervical vertebrae and the $x$-axis forming a straight line drawn perpendicular from the lower end of the fourth cervical vertebra to the $y$-axis (Figure 2). The lower end of the fourth cervical vertebra was established as the point of origin, and the upper end of the body of the hyoid bone was established as the position of the hyoid bone. The distance from the point of origin to the $x-y$ coordinates (mm) was then measured., ${ }^{2,13}$

The resting hyoid position was defined as the position of the standing hyoid with the oral cavity empty and was calculated as the vertical distance from the upper end of the hyoid bone to the $y$-axis. The maximum hyoid position was defined as the farthest displaced position during deglutition and was calculated as with resting hyoid position. The distance from the resting position to the farthest displaced position was measured and designated the maximum hyoid displacement distance. The displacement distance in the direction of the $x$-axis was calculated as the degree of anterior displacement, the displacement distance in the direction of the $y$-axis was calculated as the degree of superior displacement, and the square root of the value obtained by squaring and adding these values was calculated as the degree of hypotenuse displacement.

\section{Data processing and analysis}

Imaging software (ImageJ version 1.49; National Institutes of Health, Bethesda, MD, USA) was used for image analysis, and SPSS Statistics 20.0J software (IBM Japan, Ltd., Tokyo, Japan) was used for statistical analysis. The differences between men and women were analyzed using Mann-Whitney $U$ test. The primary purpose of this study was to determine effective correlation between jaw opening force and hyoid bone dynamics, including its position. The Spearman's rank correlation coefficient was used to examine the relationship between jaw opening force, resting hyoid position, maximum hyoid position, and degrees of anterior, superior, and hypotenuse displacements. The level of statistical significance was set at $P<0.05$.

\section{Results}

The mean ( \pm the standard deviation $[\mathrm{SD}]$ ) jaw opening force was $76.5 \pm 29.4 \mathrm{~N}$ in men and $48.1 \pm 12.7 \mathrm{~N}$ in women. A significant difference was found between men and women $(P<0.01, \gamma=0.002)$. The resting hyoid position was $8.1 \pm 7.5 \mathrm{~mm}$ in men and $8.4 \pm 8.9 \mathrm{~mm}$ in women. There was no significant difference between genders. The degree of hyoid displacement in each direction is shown in Table 1. Although no significant difference between genders was found in forward displacement, there were significant differences between genders in upward and hypotenuse displacements ( $P=0.01, \gamma=0.005$ and $P=0.05, \gamma=0.010$, respectively).

In men, there was a positive correlation between jaw opening force and resting hyoid position $(R=0.723 ; P=0.002)$ and negative correlations with all the degrees of anterior, superior, and hypotenuse displacements of the hyoid bone ( $R=-0.511, P=0.043 ; R=-0.821, P=0.000$; and $R=-0.799$, $P=0.000$, respectively; Table 2). In women, there was no statistically significant correlation between jaw opening force and any of the measurement items. There was no statistically significant correlation between jaw opening force and maximum hyoid position in either men or women (Table 2). 
Table I Participant characteristics and hyoid displacement

\begin{tabular}{|c|c|c|c|}
\hline & Men & Women & $\begin{array}{l}\text { Mann-Whitney } \\
U \text { test (P-value) }\end{array}$ \\
\hline $\mathrm{n}$ & 16 & 20 & \\
\hline Age (mean \pm SD) & $76.6 \pm 5.7$ & $74.6 \pm 6.9$ & \\
\hline $\begin{array}{l}\text { Resting hyoid position, } \\
\mathrm{mm} \text { (mean } \pm S D)\end{array}$ & $8.1 \pm 7.5$ & $8.4 \pm 8.9$ & 0.774 \\
\hline $\begin{array}{l}\text { Maximum hyoid position, } \\
\mathrm{mm}(\text { mean } \pm \mathrm{SD})\end{array}$ & $29.3 \pm 6.0$ & $22.7 \pm 8.0$ & $0.011^{\mathrm{a}}$ \\
\hline $\begin{array}{l}\text { Jaw opening force, } \\
N(\text { mean } \pm S D)\end{array}$ & $76.5 \pm 29.4$ & $48.1 \pm 12.7$ & $0.002^{\mathrm{b}}$ \\
\hline $\begin{array}{l}\text { Forward displacement, } \\
\mathrm{mm} \text { (mean } \pm S D)\end{array}$ & $10.5 \pm 4.0$ & $10.4 \pm 3.3$ & 0.924 \\
\hline $\begin{array}{l}\text { Upward displacement, } \\
\mathrm{mm} \text { (mean } \pm \text { SD) }\end{array}$ & $21.2 \pm 6.3$ & $14.3 \pm 6.4$ & $0.005^{b}$ \\
\hline $\begin{array}{l}\text { Hypotenuse displacement, } \\
\mathrm{mm}(\text { mean } \pm \mathrm{SD})\end{array}$ & $23.8 \pm 6.9$ & $18.4 \pm 5.0$ & $0.010^{\mathrm{a}}$ \\
\hline
\end{tabular}

Note: ${ }^{\mathrm{P}}<0.05,{ }^{\mathrm{b} P}<0.01$.

Abbreviation: SD, standard deviation.

\section{Discussion}

Resting hyoid position and hyoid displacement are important indices for evaluating swallowing function. However, videofluoroscopic swallowing test must be performed to evaluate hyoid bone position, and this is often clinically inapplicable in cases where there is a risk of radiation exposure and the patient is confined to bed. In contrast, the jaw opening force sthenometer that we developed is portable, has no associated risks, and is extremely simple to use. As for jaw opening force, hyoid resting position and hyoid dynamics are considered to be affected directly by the suprahyoid muscles. Although a correlation was noted for males only in this study, it is notable that we discovered a simple method for determining laryngeal swallowing dynamic function in the form of hyoid elevation and hyoid position.

\section{Relationship between jaw opening force and resting hyoid position}

This study examined elderly individuals aged $\geq 65$ years and revealed a correlation between jaw opening force and resting hyoid position only in men. Lowering of the larynx and hyoid is believed to result from age-related atrophy of the suprahyoid muscle fibers, reduced tension, and loosening of the ligaments. ${ }^{14}$ On the other hand, a previous study reported that when comparing jaw opening force in healthy individuals, the strength of the suprahyoid muscles was lower in those aged $\geq 70$ years than in those aged $<70$ years. ${ }^{9}$ Greater jaw opening force leads to higher hyoid position at rest because when measuring jaw opening force, the muscles and joints are in a fixated position. Therefore, it may reflect the strength of slow muscles (type I muscle fibers), which maintain stationary positions, more than fast muscles (type II muscle fibers). In addition, as reported elsewhere, increased muscle length may alter the fine balance of muscle properties and joint kinematics that combine to produce force. ${ }^{15}$ It suggests that longer muscles are built for excursion and shorter ones for force. Age-related changes in the endocrine system in terms of insulin-like growth factor 1 (IGF-1) and testosterone are believed to partially explain why the rate of decrease in muscle mass and muscle strength is greater in men than in women. In men, hormones, such as IGF-1 and testosterone, which have an anabolic effect on skeletal muscle are reported to be particularly prone to age-related changes. ${ }^{16}$ Decreases in blood levels of these hormones could render men more susceptible to reductions in skeletal muscle mass. Moreover, although differences in physique were not considered in this study, the fact that men with relatively larger physiques are more affected by gravity than women may be one of the reasons why men were more likely to exhibit lowering of the hyoid bone due to decreased muscle strength. In fact, a comparison of measurements of hyoid position from the lower jaw using computed tomography by age group and gender showed an increase in this distance only in male elderly individuals, whereas no age-related change was observed in women. ${ }^{17}$ The distance between the hyoid bone and lower jaw, therefore, appears to be significantly greater in elderly men than in elderly women. Because the SD in the female cohort was small and in the male cohort was large in a small sample size, it is also assumed that $r$ values were not significant in

Table 2 Correlation of jaw opening force with resting/maximum hyoid position and hyoid displacement

\begin{tabular}{|c|c|c|c|c|c|}
\hline & $\begin{array}{l}\text { Resting hyoid } \\
\text { position }\end{array}$ & $\begin{array}{l}\text { Maximum } \\
\text { hyoid position }\end{array}$ & $\begin{array}{l}\text { Forward } \\
\text { displacement }\end{array}$ & $\begin{array}{l}\text { Upward } \\
\text { displacement }\end{array}$ & $\begin{array}{l}\text { Hypotenuse } \\
\text { displacement }\end{array}$ \\
\hline \multicolumn{6}{|l|}{ Men } \\
\hline Spearman's $R$ & $0.723^{\mathrm{a}}$ & 0.000 & $-0.51 \mathrm{I}^{\mathrm{a}}$ & $-0.821^{b}$ & $-0.799^{b}$ \\
\hline$P$-value & 0.002 & 1.000 & 0.043 & 0.000 & 0.000 \\
\hline \multicolumn{6}{|l|}{ Women } \\
\hline Spearman's $R$ & -0.004 & -0.018 & 0.086 & -0.123 & -0.094 \\
\hline$P$-value & 0.987 & 0.938 & 0.719 & 0.604 & 0.693 \\
\hline
\end{tabular}

Note: ${ }^{\mathrm{P}}<0.05,{ }^{\mathrm{b} P}<0.01$. 
females and were significant in males. However, women may have a protective "flexibility" in the oropharyngeal swallow mechanism that allows them to better compensate for aging than men as Logemann et al ${ }^{1}$ have suggested. Perhaps through adaptation in aging, the muscle architecture changed and these physiological differences are seen in the data.

\section{Relationship between jaw opening force and hyoid movement}

In men, there was a negative correlation between jaw opening force and all the degrees of superior, anterior, and hypotenuse displacements of the hyoid bone during swallowing. As presented in the results (Table 2), a possible reason is that a greater jaw opening force elevates the resting position of the hyoid bone, thereby shortening the distance that the hyoid bone is pulled. Our study showed no correlation between jaw opening force and maximum hyoid elevation in both males and females, which was consistent with the findings of a previous report indicating that there were no clear aging-related changes in maximum hyoid elevation during swallowing. ${ }^{14}$ The elevation distance necessary to achieve normal swallowing increases when the resting position of the hyoid lowers as a result of age. ${ }^{17}$ A high hyoid position can be advantageous for swallowing because effective elevation can be achieved to prevent aspiration with minimal movement, which explains why the degree of hyoid elevation is increased in elderly men with a lowered hyoid position. However, according to previous reports, elderly men experience less hyoid elevation than young men. ${ }^{1,2}$ Because this study only examined healthy individuals, no subjects experienced any aspiration or noticeable residue even with a lowered resting hyoid position. Nonetheless, in a past report that examined dysphagia caused by conditions such as cerebrovascular disease, neuromuscular disease, and disuse syndrome, findings of aspiration and pharyngeal residue in the group of subjects with reduced jaw opening force suggested that the disability-related inability to compensatorily increase the elevation distance of the hyoid lowered as a result of low jaw opening force is the cause of these abnormal findings. ${ }^{10}$

\section{Conclusion}

The results of this study suggest that a low jaw opening force results in a low resting hyoid position only in elderly men. Moreover, a low hyoid position in elderly men was found to result in a compensatory increase in the total degree of hyoid movement during swallowing, and a maximum hyoid position in healthy individuals of either gender does not differ depending on their jaw opening force.

\section{Study limitations}

The degree of hyoid bone displacement during swallowing of fluids, resting hyoid position, and jaw opening force was only evaluated in healthy elderly individuals. Going forward, further experiments using the same methods will be needed to compare and examine the results of healthy adult men and women with those of the healthy elderly men and women in this study. We also intend to include jaw opening force, resting hyoid position, and hyoid bone movement as variables for examination in those with and without sarcopenia and with dysphagia caused by cerebrovascular disease and/or neuromuscular disease.

\section{Disclosure}

The authors report no conflicts of interest in this work.

\section{References}

1. Logemann JA, Pauloski BR, Rademaker AW, Kharilas PJ. Oropharyngeal swallow in younger and older women; videofluoroscopic analysis. J Speech Lang Hear Res. 2002;45(3):434-445.

2. Logemann JA, Pauloski BR, Rademaker AW, Colangelo LA, Kahrilas PJ, Smith CH. Temporal and biomechanical characteristics of oropharyngeal swallow in younger and older men. J Speech Lang Hear Res. 2000;43(5):1264-1274.

3. Perlman AL, Booth BM, Grayhack JP. Videofluoroscopic predictors of aspiration in patients with oropharyngeal dysphagia. Dysphagia. 1994;9(2):90-95.

4. Furukawa K. Cineradiographic analysis of laryngeal movement during deglitution. Nippon Jibiinkoka Gakkai Kaiho. 1984;87(2): 169-181.

5. Jacob P, Kahrilas PJ, Logemann JA, Shah V, Ha T. Upper esophageal sphincter opening and modulation during swallowing. Gastroenterology. 1989;97(6):1469-1478.

6. Cook IJ, Dodds WJ, Dantas RO, et al. Timing of videofluoro-scopic, manometric events, and bolus transit during the oral and pharyngeal phases of swallowing. Dysphagia. 1998;4:8-15.

7. Pearson WG Jr, Langmore SE, Zumwalt AC. Evaluating the structural properties of suprahyoid muscles and their potential for moving the hyoid. Dysphagia. 2011;26(4):345-351.

8. Tohara H, Wada S, Sanpei R, et al. Development of a jaw-opening sthenometer to assess swallowing functions. First report: jaw opening muscle strength of healthy volunteers. Jpn Soc Gerodontol. 2011;26: $78-84$.

9. Iida T, Tohara H, Wada S, Nakane A, Sanpei R, Ueda K. Aging decreases the strength of suprahyoid muscles involved in swallowing movements. Tohoku J Exp Med. 2013;231(3):223-228.

10. Hara K, Tohara H, Wada S, Iida T, Ueda K, Ansai T. Jaw-opening force test to screen for dysphagia: preliminary results. Arch Phys Med Rehabil. 2014;95(5):867-874.

11. Mays KA, Palmer JB, Kuhlemeier KV. Influence of craniofacial morphology on hyoid movement: a preliminary correlational study. Dysphasia. 2009;24(1):71-76.

12. Cook IJ, Dodds WJ, Dantas RO, et al. Opening mechanisms of the human upper esophageal sphincter. Am J Physiol. 1989;257(5 Pt 1): 748-759.

13. Steele CM, Bailey GL, Chau T, et al. The relationship between hyoid and laryngeal displacement and swallowing impairment. Clin Otolaryngol. 2011;36:30-36. 
14. Kaneko I. A cinefluorographic study of hyoid bone movement during deglutition. Nippon Jibiinkoka Gakkai Kaiho. 1992;95(7):974-987.

15. Lieber RL, Boakes JL. Sarcomere length and joint kinematics during torque production in frog hindlimb. Am J Physiol. 1988;254(6 Pt 1): 759-768.

16. Albani D, Batelli S, Polito L, et al. A polymorphic variant of the insulinlike growth factor 1 (IGF-1) receptor correlates with male longevity in the Italian population: a genetic study and evaluation of circulating IGF-1 from the "Treviso Longeva (TRELONG)" study. BMC Geriatr. 2009;9:19.
17. Feng $\mathrm{X}$, Todd $\mathrm{T}, \mathrm{Hu} \mathrm{Y}$, et al. Age-related changes of hyoid bone position in healthy older adults with aspiration. Laryngoscope. 2014; 124(6):231-236.

\section{Publish your work in this journal}

Clinical Interventions in Aging is an international, peer-reviewed journal focusing on evidence-based reports on the value or lack thereof of treatments intended to prevent or delay the onset of maladaptive correlates of aging in human beings. This journal is indexed on PubMed Central, MedLine,
CAS, Scopus and the Elsevier Bibliographic databases. The manuscript management system is completely online and includes a very quick and fair peer-review system, which is all easy to use. Visit http://www.dovepress. com/testimonials.php to read real quotes from published authors. 